\title{
Investigação em Ambiente em tempos de pandemia
}

\author{
https://doi.org/10.21814/uminho.ed.24.15
}

\section{Teresa Valente}

Teresa Valente (ORCID: 0000-0002-7293-3825) é Professora Auxiliar com agregação no Departamento de Ciências da Terra da Escola de Ciências da Universidade do Minho e investigadora do Centro de Ciências da Terra da mesma Universidade. Licenciada em Engenharia do Ambiente pela Universidade de Aveiro, é mestre em Ciências do Ambiente - Qualidade Ambiental e doutorada em Geologia pela Universidade do Minho. As suas áreas de especialização enquadram-se no âmbito da Geologia Ambiental e das Ciências do Ambiente, com grande foco no binómio atividade mineira-ambiente. 
Não querendo ser repetitiva, eis que a COVID-19 nos pôs a viver uma crise sem precedentes na nossa geração e com efeitos em todos os aspetos de uma Sociedade Humana que se globalizou. Por indissociabilidade do terrível significado do termo pandemia, os seus impactes são apátridas e democráticos. A tão marcada separação Norte-Sul, países desenvolvidos-países em desenvolvimento, democracias-ditaduras não é fronteira para o SARS-coronavírus 2 (SARS-CoV-2). O mesmo não se pode dizer da capacidade de reação das naçóes, balizada pelo nível díspar de desenvolvimento socioeconómico e opções políticas.

A natureza universal deste vírus manifesta-se, também, pela dispersão dos impactes por todos os compartimentos do planeta Terra. O Ambiente, na sua aceção mais vasta, contemplando todas as geosferas (hidrosfera, atmosfera, biosfera, litosfera, pedosfera, Figura 1) pode ser limitante e, ao mesmo tempo, ver-se limitado pela ação do vírus.
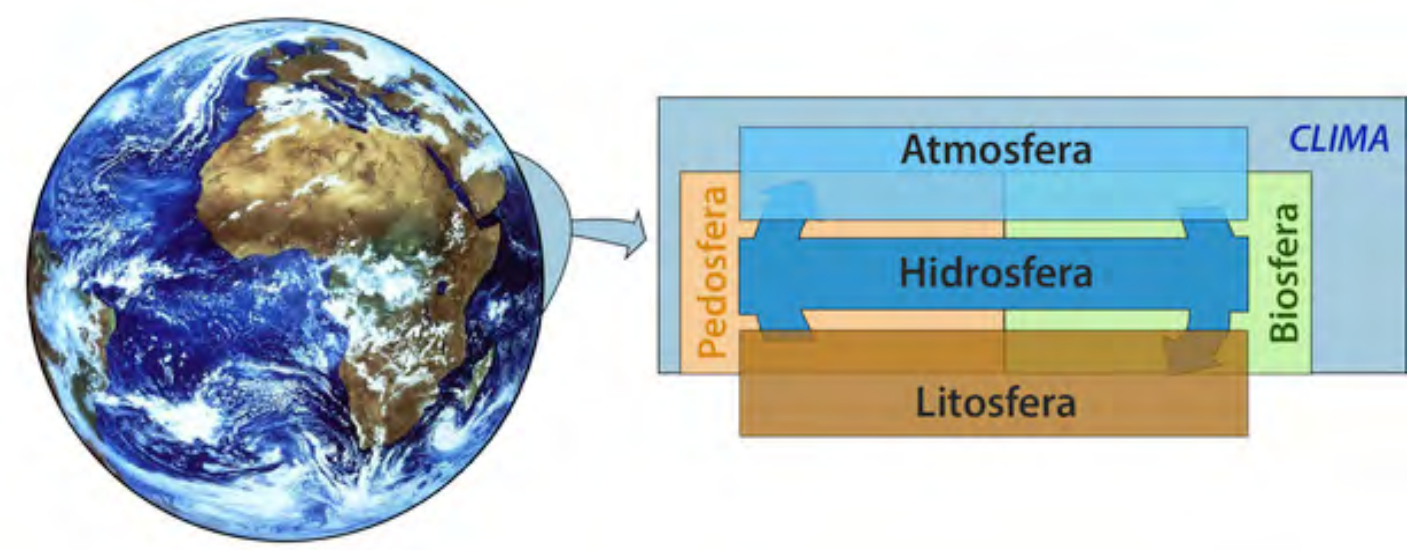

Figura 1. Geosferas terrestres superficiais, principais reservatórios de poluentes - interações entre o ar, água, solo, recursos geológicos e seres vivos.

Num breve curto espaço de tempo, entre março e maio de 2020, surgiu um enorme volume de publicações com contribuições para fazer face à diversidade de problemas criados pelo vírus, incluindo as respostas ao confinamento. As Ciências e Tecnologias do ambiente não foram exceção.

A industrialização crescente nestas duas últimas décadas, bem como as restantes atividades antropogénicas, viram-se subitamente limitadas ou mesmo interrompidas 
em muitas partes do globo. Este abrandamento gerou empiricamente a perceção de uma diminuição da poluição, por exemplo do ar e da água.

Enquanto esta melhoria da qualidade do ambiente se tornava um objeto mediático (Figura 2), despontava a determinação, motivada pela curiosidade científica, de investigar as várias facetas desta realidade. Orientados pelos preceitos do método científico surgem então trabalhos que, ora levantam hipóteses, ora discutem resultados que comprovam ou desmontam ideias pré-concebidas sobre os efeitos do confinamento nos vários reservatórios de poluentes.

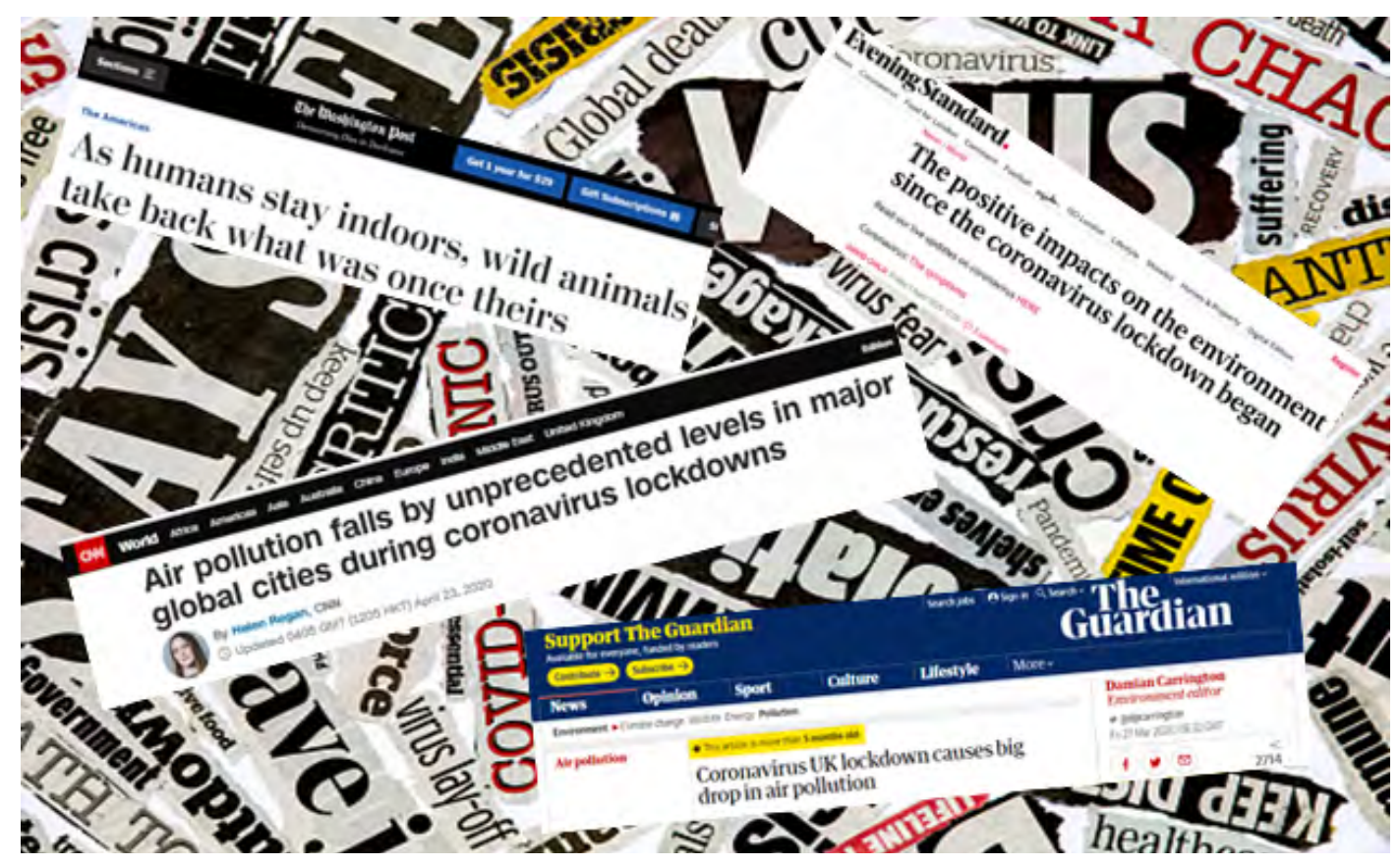

Figura 2. Exemplos do carácter mediático das consequências ambientais associadas ao confinamento. Imagem de fundo adquirida no GettyImage. Manchetes adaptadas de printscreens das páginas de internet dos media.

É assim que surge esta reflexão, que procura mostrar pontos de vista, ações e reações sobre o Ambiente e a investigação que tem emanado desta crise. Mas que grande desafio é partilhar o ponto de vista de colegas e grupos de investigação que trabalham numa área tão vasta, que cobre o céu, o mar, e a terra! Que impactes se avaliam ou se preveem sobre os rios, a água que bebemos, o solo que nos alimenta, a biodiversidade que nos suporta? E como fazer isto num cenário de confinamento que cria uma 
multitude de dificuldades para obter dados fiáveis e consistentes? Por exemplo, como lidar com as dificuldades de fazer trabalho de campo, aquele que proporciona os instrumentos primários para monitorizar o Ambiente?

Este capítulo assume-se então humildemente como uma revisão do estado da arte na ampla e multifacetada área do Ambiente, partilhando os desafios que esta investigação enfrenta nestes inusitados tempos da COVID-19.

\section{AMBIENTE - CONCEITO, COMPONENTES E INSTRUMENTOS DE IN- VESTIGAÇÃO EM CIÊNCIAS DO AMBIENTE}

Não é fácil, ou sequer de grande utilidade, desenvolver muitos esforços para definir Ambiente. Qualquer aceção que se apresente não é universal e, portanto, também não será consensual. No entanto, apenas para nosso entendimento da vastidão de interaçốes em causa, eis o conceito apresentado na primeira Lei de Bases da Política de Ambiente em Portugal (Lei no 11/87, de 07 de abril):

"Ambiente é o conjunto dos sistemas físicos, químicos, biológicos e suas relaçốes e dos factores económicos, sociais e culturais com efeito directo ou indirecto, mediato ou imediato, sobre os seres vivos e a qualidade de vida do homem”.

Esta aceção reflete o espaço biofísico, entendido de forma simplista como território associado a valores biológicos e geológicos, bem como às perspetivas socioeconómicas que asseguram a adequabilidade dos vários sistemas às necessidades do homem. É um conceito amplo, multifacetado e adaptável (Sanchez, 2013).

O Ambiente pode ser estudado de forma holística ou mais ou menos enfocada. Em qualquer dos casos, a investigação faz-se sobre os denominados "componentes ambientais". Este é outro conceito cuja definição não colhe unanimidade. Assim, para acautelar discórdias refere-se aqui o parecer, mais geral, que considera a existência de componentes ambientais naturais e humanos. Este é também um entendimento legal (Lei de bases do Ambiente, Lei no 19/2014 de 14 de abril), que inclui nos componentes naturais o ar, a água e o mar, a biodiversidade, o solo e o subsolo, a paisagem e os recursos naturais. Alterações climáticas, resíduos, ruído e produtos 
químicos são, por sua vez, considerados componentes associados a comportamentos humanos.

Compreender os fenómenos naturais e as perturbações observadas nestes componentes determina a aplicação de princípios, conceitos e métodos, integrados no âmbito alargado das Ciências do Ambiente. Portanto, a investigação em Ciências do Ambiente contempla inúmeros fatores, sistemas e interaçôes, donde emana a necessidade de uma grande diversidade de ferramentas (Figura 3). Estas proveem das Ciências Naturais, às quais associamos, por exemplo, o estudo dos ecossistemas e dos recursos naturais. Mas os problemas ambientais são também sociais, exigem mediação política e a sua remediação obriga a intervenções tecnológicas. Com efeito (alínea c, artigo 4º do capítulo I da Lei 19/2014 de 14 de abril):

"o diagnóstico e as soluçóes dos problemas ambientais devem resultar da convergência dos saberes sociais com os conhecimentos científicos e tecnológicos, tendo por base dados rigorosos, emanados de fontes fidedignas e isentas".

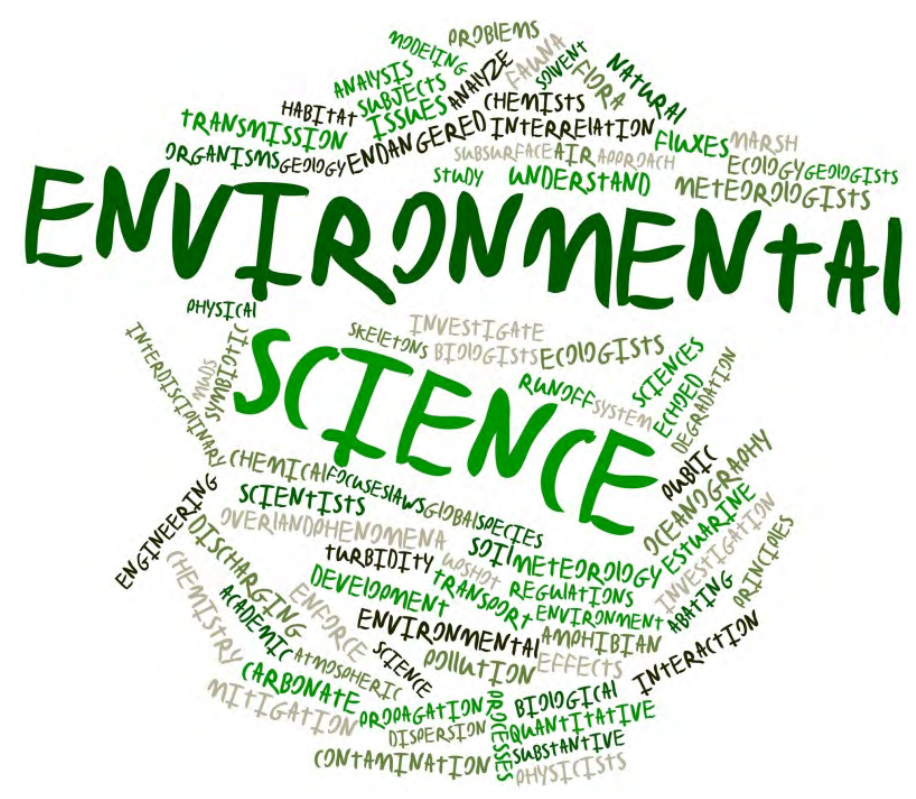

Figura 3. As Ciências do Ambiente enquanto reunião de domínios científicos.

Grafismo do artista Radiantskies, adquirida a Publitek, Inc. dba GoGraph.

A investigação em Ciências do Ambiente é pois necessariamente multidisciplinar, o que ganha ainda mais significado no contexto desta pandemia. As causas e efeitos 
do SARS-CoV-2 têm sido estudados considerando uma grande variedade de âmbitos que se enquadram nas Ciências do Ambiente.

Apontam-se desde logo os componentes naturais, mas estes estão necessariamente em interação com todos os fatores que condicionam o funcionamento das sociedades humanas. Por exemplo, aspetos como a origem e a dispersão do vírus têm sido relacionados com eventuais disrupções na gestão da fauna e das florestas (Dobson et al., 2020; Tollefson, 2020) bem como com variaçôes de temperatura e humidade (Lal et al., 2020; Ma et al., 2020; Sajadi et al., 2020; Wu et al., 2020). Por sua vez, os componentes ambientais naturais "ar" e "água" têm sido frequentemente tratados ao nível dos benefícios ou danos provocados pelo confinamento (e.g., Yunus et al., 2020; Zambrano-Monserrate et al., 2020). Muitos outros tópicos envolvendo a COVID-19, tão variados como a evolução das curvas de contágio, condições sanitárias, produção de resíduos e efluentes, consumo de água, emprego e crise económica, vieram pôr em evidência a importância de encarar a investigação deste tema no âmbito das ciências do ambiente e, portanto, de forma multidisciplinar e transversal.

\section{IMPACTE AMBIENTAL DA COVID-19}

O conceito de impacte ambiental e de avaliação de impactes são classicamente usados como ferramentas técnicas e instrumentos políticos, essenciais para a gestão sustentável do Ambiente. De acordo com os princípios da avaliação de impacte ambiental, os efeitos de uma dada atividade ou projeto são classificados como positivos, negativos ou nulos. A avaliação faz-se componente a componente. Ou seja, caraterizam-se e avaliam-se os efeitos das açóes que compóem a atividade sobre os vários componentes ambientais.

Na literatura científica produzida nestes tempos de pandemia assistiu-se à extensão do conceito clássico de impacte ambiental, procurando agora classificar e avaliar as suas consequências ambientais. A breve revisão do estado da arte que aqui se apresenta mostra abordagens de investigação e visões variadas sobre os impactes, classificados como positivos, negativos ou ambíguos, de acordo com a terminologia de Bobylev (2020), na sua reflexão sobre a relação entre o Ambiente e a crise económica provocada pela pandemia. 


\section{Produção cientifica-abordagens e disparidades}

O interesse mediático e científico da relação entre a pandemia e o Ambiente reflete-se na elevada produção científica que se observou num tão curto período de tempo. Disso é exemplo o trabalho publicado por Cheval et al. (2020) que apresentam 142 referências, maioritariamente de artigos científicos e capítulos de livros indexados em bases de dados como a Web of Science e Scopus. Estes alicerçam o interesse deste tópico na influência que os fatores ambientais exercem na disseminação do vírus e consequente necessidade de realizar estudos que considerem a interação do coronavírus com aspetos sociais e ecológicos.

Podem citar-se alguns trabalhos de carácter amplo, que abordam impactes sobre vários componentes. É o caso do artigo de Zambrano-Monserrate et al. (2020), que aborda a evolução das concentraçôes de $\mathrm{NO}_{2}$ no ar na China, a qualidade da água das praias a nível global, mas também se debruça sobre componentes humanas, como a diminuição do ruído e o aumento da produção de resíduos, incluindo os plásticos. No entanto, a maioria das publicações centra-se nalgum componente específico.

Com efeito, é de notar o tratamento díspar que a comunidade científica pareceu dar aos vários componentes ambientais. A atmosfera foi sem dúvida a geosfera que gerou maior número de publicaçôes em revistas científicas, com resultados sobre a evolução da qualidade do ar em todos os continentes.

Outras geosferas, que abrangem componentes como a água (hidrosfera), vida selvagem e biodiversidade (biosfera) e solo (pedosfera) não originaram o mesmo volume de artigos. Apesar disto, o interesse científico manifestou-se igualmente através de fóruns de discussão, blogues e redes sociais.

Esta desigualdade reflete a natureza, também ela díspar, dos métodos e técnicas de investigação nas diferentes áreas. A deteção remota, tão útil em estudos sobre a qualidade do ar, é também cada vez mais usada noutros domínios. No entanto, não substitui ferramentas de trabalho que são críticas nos protocolos de monitorização de ecossistemas e geossistemas. É certo que muitos dos grandes rios e lagos do mundo possuem estaçóes automáticas que permitem a colheita de dados. No entanto, o controlo é normalmente estrito, contemplando um reduzido número de parâmetros. 
Em muitos cenários pelo mundo fora, como monitorizar pequenos cursos de água, poços, furos ou o solo por vezes em locais remotos? O confinamento limitou deveras, ou tornou mesmo impossível a realização de trabalho de campo. Esta dificuldade estendeu-se aos laboratórios. Nas instituições de investigação, o trabalho laboratorial foi naturalmente orientado para fazer face às exigências de controlo do vírus, deixando para trás o tratamento analítico de amostras, por exemplo de água, sedimentos ou solo.

Como paradigma das abordagens de investigação em Ambiente, seguem-se alguns exemplos que incidem sobre dois dos componentes mais estudados em tempo de pandemia.

\section{Impactes sobre o ar}

Durante o confinamento fomos frequentemente regalados, ou antes invadidos, com notícias sobre as melhorias significativas da qualidade do ar nas cidades. A redução da circulação de transportes, incluindo a aviação, e da atividade industrial em geral, que acompanhou a crise económica global, foi apontada como responsável por diminuições importantes nas emissões de gases com efeito de estufa e outros poluentes da atmosfera. Neste âmbito, a produção científica foi de facto profícua, ainda que pouco diversificada.

Genericamente, nos artigos publicados em revistas de elevado impacto e reputação internacional (e.g., Science of the Total Environment; Environmental Pollution; International Journal of Environmental Research and Public Health) o tema aparece exposto com formato idêntico, usando dados obtidos de forma análoga. Esta proximidade nas abordagens é natural, uma vez que o pouco tempo decorrido não permitiu que os vários grupos de investigação recolhessem os seus próprios dados, ficando quase sempre reféns do tratamento de informação obtida remotamente (estações de colheita automáticas e imagens de satélite). Citam-se, a título de exemplo, publicaçóes que recorrem a este tipo de informação, disponibilizada por entidades oficiais, com caráter regional, nacional ou internacional (e.g., Collivignarelli et al., 2020; Dutheil et al., 2020; Ficetola e Rubolini, 2020; Kerimray et al., 2020; Lal et al., 2020; Li et al., 2020; Muhammad et al., 2020). 
A observação do efeito das medidas de confinamento sobre a qualidade do ar motivou também abordagens de modelação matemática, no sentido de comprovar análises empíricas. Cita-se como exemplo a investigação de Bao e Zhang (2020), que determinam índices de qualidade do ar antes e após o confinamento em 44 cidades da China, com base na modelação de concentrações de poluentes atmosféricos ( $\mathrm{SO}_{2}, \mathrm{PM} 2.5, \mathrm{PM} 10, \mathrm{NO}_{2}$, e CO), obtidas entre dezembro e março de 2020.

Saadat et al. (2020) apresentam uma visão global, quantificando a diminuição de emissões de poluentes atmosféricos em várias partes do mundo. Estes autores referem um decréscimo de $50 \%$ dos níveis de poluição do ar em Nova Iorque, apontando para uma diminuição de $25 \%$ de emissóes na China.

Em síntese, a investigação no âmbito da componente “ar" orientou-se segundo dois vetores principais: análise e discussão de dados de deteção remota e modelação com base em informação obtida antes da pandemia. As duas abordagens procuraram estabelecer a evolução da qualidade do ar face à implementação das medidas de confinamento (abordagem do tipo "antes e depois"), usando recorrentemente imagens de satélite, como as das Figuras 4 e 5.

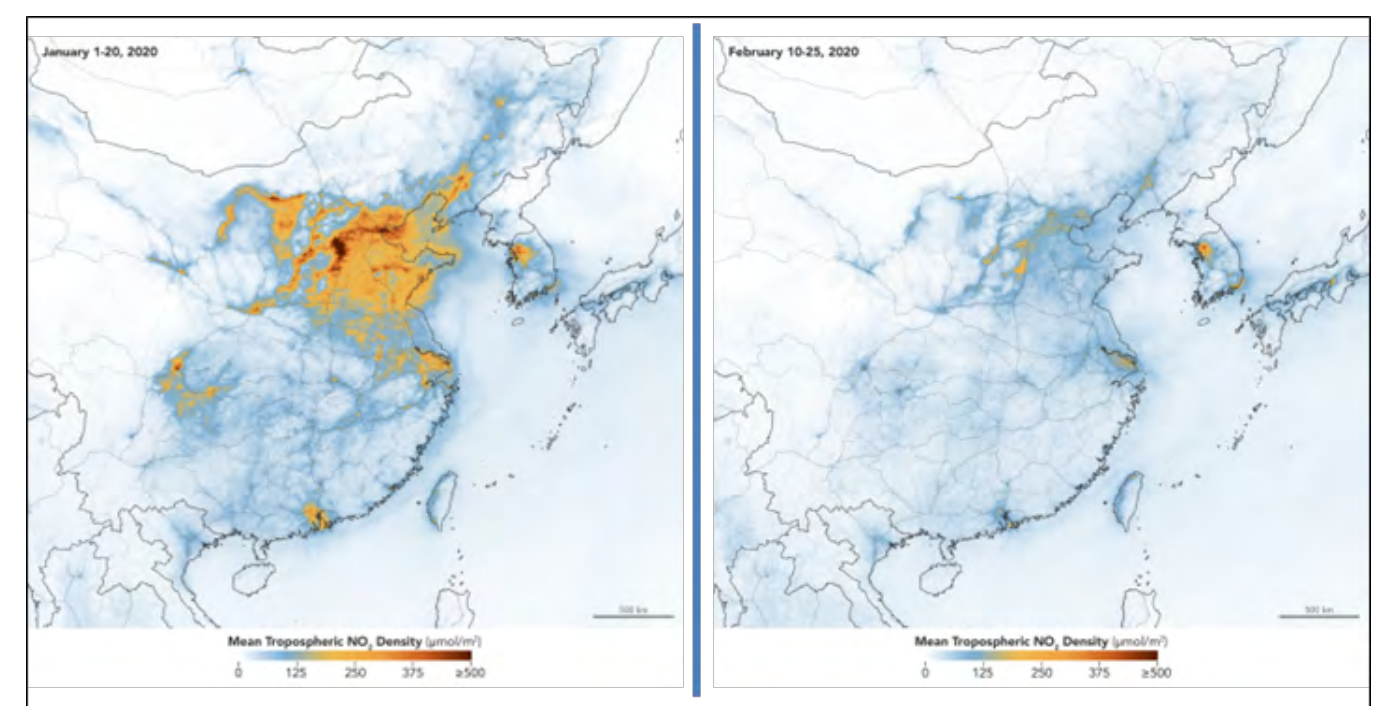

Figura 4. Evolução da concentração de $\mathrm{NO}_{2}$ na China. Adaptada de NASA (2020). 


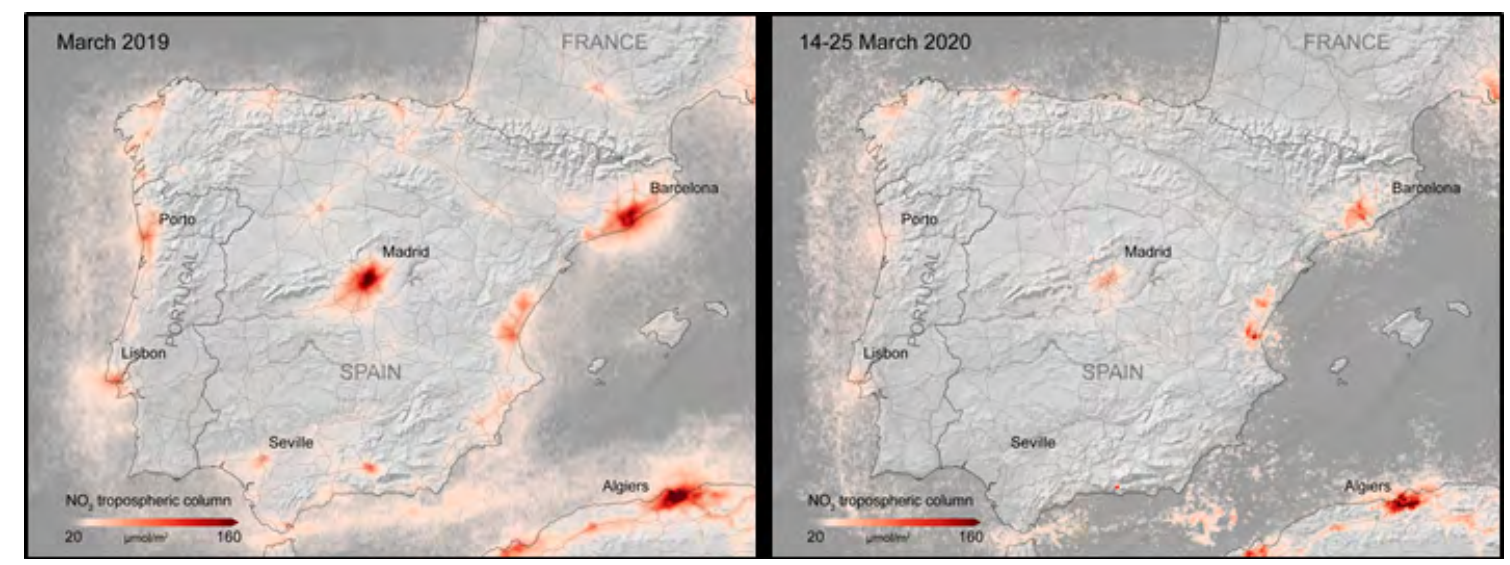

Figura 5. Evolução da concentração de $\mathrm{NO}_{2}$ na Península Ibérica. Adaptada de ESA (2020).

\section{Impactes sobre a água}

A água, componente essencial à vida, tem sido alvo de investigação orientada principalmente ao tema da qualidade. Os canais de Veneza tornaram-se um exemplo mediático e paradigmático em vários sentidos. No início de março apareceram notícias, por exemplo reportando a aparição de fauna marinha (golfinhos) há muito desaparecida, mas que se vieram a comprovar como falsas ou exageradas (Newton, 2020). Um fato científico foi a diminuição da turvação da água devido à deposição de sedimentos provocada pelo decréscimo de tráfego e movimentação da água. No entanto, não há evidência científica de melhoria noutros indicadores de qualidade da água. Apesar disto, maior transparência significa que a luz solar pode penetrar até maior profundidade, beneficiando os organismos bênticos. O fundador do "The Venice Resilience Lab", Giovanni Cecconi, refere ao EuroNews (https://www.euronews.com), a importância ecológica e política desta constatação, defendendo que a estratégia para a recuperação futura de todo o ecossistema da Lagoa de Veneza pode passar pelo controlo da matéria particulada.

Braga et al. (2020) apresentam um estudo muito completo baseado em imagens de satélite sobre o efeito do confinamento na transparência da água da Lagoa de Veneza. Os autores concluem que se trata de uma condição transitória, resultante de uma combinação de fatores sazonais com a calmaria do confinamento. Realçam, no entanto, a necessidade de estudos complementares baseados na colheita de amostras e na sua caracterização físico-química e biológica. 
Apesar das inúmeras menções ao tema, principalmente através de registos noticiosos e diversos blogues, não abundam artigos científicos que reportem o efeito da pandemia sobre a qualidade da água, principalmente a água subterrânea. São ainda menos os que abordam os recursos hídricos na aceção da quantidade e eventuais efeitos sobre os aspetos hidrogeológicos, o que se poderá explicar pela dificuldade de obter dados em situação de confinamento.

Podem, ainda assim, citar-se alguns trabalhos interessantes que, de forma similar ao que se apresentou para o ar, analisam "o antes e depois". O referido obstáculo na obtenção de dados é mencionado por vários investigadores, nomeadamente Braga et al. (2020), no estudo acima citado sobre Veneza e por Yunus et al. (2020), num trabalho que avalia o efeito das restrições na atividade industrial durante o confinamento sobre o maior lago da China. Também neste último caso, a investigação recorre a imagens de satélite, mas usa o único parâmetro disponível (matéria particulada em suspensão). Os autores sugerem um padrão de melhoria na qualidade da água, com uma diminuição de $16 \%$ da referida matéria, comparativamente com a situação pré-pandemia. No entanto, discutem as limitações da sua investigação, apontando a necessidade de ferramentas complementares.

Lokhandwala e Gautam (2020) apresentam uma abordagem idêntica, com base em dados de estações de colheita automática, registando incrementos na concentração de oxigénio dissolvido em grandes rios da Índia. Os autores associam esta melhoria da qualidade da água a restriçóes nas atividades antropogénicas, como a indústria e a agricultura. No entanto, discutem também a possibilidade dos parâmetros estarem influenciados por fatores naturais como a diluição provocada pelo degelo sazonal. Isso mesmo é reforçado pela investigação de Dutta et al. (2020) que sugerem o efeito da precipitação especialmente elevada que se observou este ano na bacia do rio Ganges.

Como exemplo de uma abordagem diferente na investigação da componente água cita-se o artigo de Selvam et al. (2020). Estes autores estudaram a qualidade da água subterrânea numa cidade industrial da Índia, com base na colheita de amostras e análise de parâmetros físico-químicos (e.g., nitratos, metais e arsénio) e biológicos 
(coliformes totais e coliformes fecais). Os autores concluíram que as medidas de restrição à atividade industrial resultaram numa diminuição da concentração de poluentes.

Os exemplos apresentados sugerem que os impactes sobre a qualidade da água, superficial e subterrânea, foram positivos. O confinamento traduziu-se numa melhoria, que se relacionou quase sempre com a diminuição da atividade industrial. Os resultados obtidos durante a pandemia demonstram também a necessidade de controlar as emissões de efluentes domésticos e industriais, nomeadamente nos países em desenvolvimento, como estratégia primordial de gestão da qualidade da água.

As reaçôes à pandemia merecem ainda uma observação sobre o valor do recurso “água”, num contexto de escassez cada vez mais premente em muitas partes do globo, incluindo Portugal.

Embora de forma muito heterogénea, função dos modelos de desenvolvimento económico e dos paradigmas sociais, políticos e culturais de cada comunidade, "ficar em casa" faz aumentar o consumo de água. Heather Cooley do Pacific Institute (https://pacinst.org/) refere a este propósito aumentos de consumo doméstico superiores a 10-15\% em Inglaterra (Portsmouth) e nos Estados Unidos (São Francisco). Pelo contrário, a mesma fonte aponta para decréscimos no consumo não residencial, que atingem os $32 \%$.

Por exemplo, as medidas de higienização frequente que entraram nas nossas rotinas implicam maior consumo de água. Isto representa implicitamente uma sobrecarga sobre os recursos hídricos e consequentemente um impacte negativo sobre este componente natural. Em muitos países em desenvolvimento, o problema assume ainda outra faceta, pondo em destaque a desigualdade no acesso a água potável. Principalmente em climas áridos, como é possível assegurar as medidas de higienização quando é necessário percorrer quilómetros para aceder a água, muitas vezes sem qualquer controlo de qualidade? A Figura 6 ilustra este panorama num país que nos é bem próximo (República de Cabo Verde), e onde esta tarefa está atribuída às mulheres e às crianças, estas últimas, que deveriam estar na escola! 


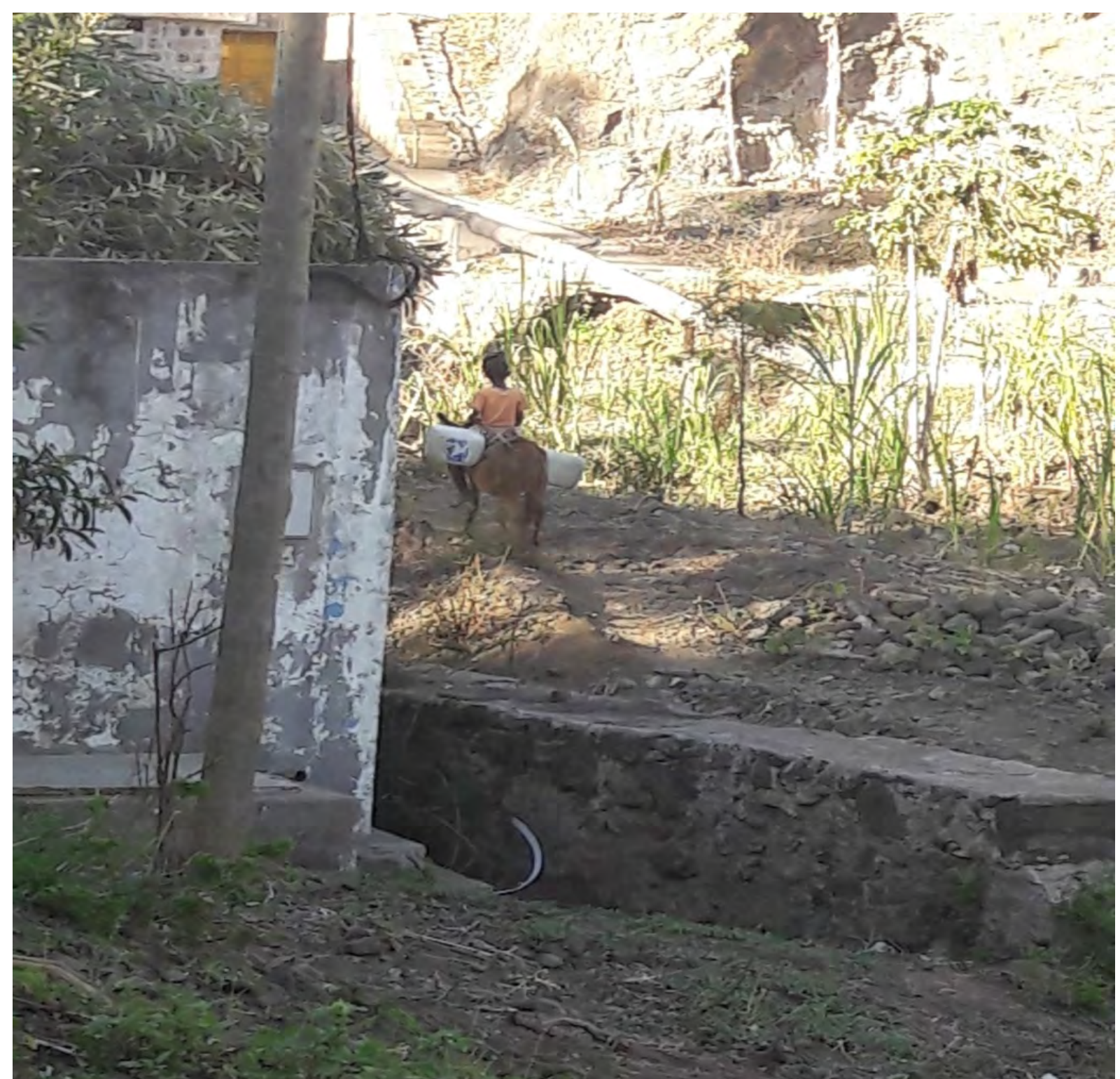

Figura 6. Criança no seu percurso diário para obter água para a família na Ilha de Santiago (Cabo Verde). Fotografia da autora.

\section{REFLEXÕES E DESAFIOS}

Em poucos meses o SARS-CoV-2 fez mudar o mundo e, portanto, mudou também o Ambiente. As atividades antropogénicas que associamos à geração de poluição e de impactes negativos pararam ou foram muito limitadas. A tão temida crise económica e sanitária teve, segundo muitos, consequências positivas para o Ambiente. Embora uma observação preliminar, por exemplo de aspetos como a qualidade do 
ar e a emissão de gases com efeito de estufa, pareça comprovar esta análise empírica, os efeitos noutros componentes são discutíveis. Mesmo o impacte sobre a água não é consensual. Num cenário de crescente escassez, o aumento do consumo associado à permanência em casa e às medidas de higienização impóem certamente uma sobrecarga sobre os recursos hídricos.

Nesta reflexão cabe, também, introduzir outras dimensões, para além do sinal positivo ou negativo dos impactes, principalmente se quisermos extrair lições úteis para a gestão dos recursos naturais não só durante a pandemia, mas também contribuir, fora dela, para a tão desejada sustentabilidade. Dimensões como a duração e reversibilidade dos impactes, associadas à capacidade de carga dos sistemas afetados urgem agora ser investigadas.

A retoma das atividades económicas é certa e, em muitos casos, já assumiu contornos normais. Em consonância, os efeitos positivos começam a desvanecer. Contamos pois com a comunidade científica que estuda o Ambiente para compreender, estimar e prever a índole, duração e significância dos impactes da reabertura económica.

Uma realidade concreta que emana desta pandemia é a multiplicidade de fatores naturais que se conjugam com componentes associados ao comportamento humano para a disseminação do vírus, assim como, para as suas consequências ambientais. Apesar de todas as incertezas potenciadas pela variedade de interações, é certo que os componentes ambientais respondem de forma mais ou menos imediata, direta ou indireta, aos ritmos das Sociedades Humanas. Mas estes efeitos, ainda que pequenos ou transitórios, mostraram a necessidade de uma gestão adequada de recursos naturais, de igualdade na sua distribuição e puseram em evidência a suscetibilidade do Ambiente à degradação, neste modelo de Sociedade.

As modificações impostas pela pandemia também se estenderam à forma de fazer investigação. Desde logo, os canais de partilha de informação a nível global (plataformas científicas e redes sociais, profissionais e generalistas) associados ao networking científico foram essenciais para o desenvolvimento de muitos projetos de investiga- 
ção neste período em que as viagens se tornaram impossíveis. $\mathrm{Na}$ área do Ambiente, a informação obtida remotamente a partir de imagens de satélite ou de estações automáticas de medição foi decisiva para a análise das perturbações em certos componentes ambientais. Apesar desta contribuição inestimável, há que apontar a enorme limitação da impossibilidade real que constitui a não realização de trabalho de campo.

O trabalho de campo é uma ferramenta primária essencial para obter dados rigorosos que reflitam padróes de evolução. Este desafio que vivemos na Universidade do Minho é partilhado por muitos colegas de outras instituições, cuja investigação aplica protocolos de colheita e monitorização da água, do solo ou da vida selvagem, entre outros componentes. Necessariamente há informação única, muita dela com carácter sazonal, que se perde para sempre.

Um desafio maior que se coloca à investigação em Ambiente, que em tempos de pandemia e pós-pandemia é ainda mais crítico, é a imensidade de interações entre as várias geosferas. Os fatores de controlo são múltiplos, pelo que o resultado em termos ambientais quase nunca é direto e, na maioria dos casos, continua a haver uma grande incerteza ou mesmo desconhecimento quanto ao sentido e dimensão dos impactes.

\section{AGRADECIMENTOS}

O meu agradecimento ao Jorge Pamplona pela sua inestimável ajuda na preparação de figuras e na leitura do texto. À Profa. Maria Amália Sequeira Braga, o meu obrigado pelo seu apoio e motivação sempre presentes e habitual olho crítico na revisão final. 


\section{BIBLIOGRAFIA}

Bao, R., Zhang, A. (2020). Does lockdown reduce air pollution? Evidence from 44 cities in northern China. Science of The Total Environment 731, 139052. https://doi.org/10.1016/j.scitotenv.2020.139052. Bobylev, S.N. (2020). Environmental consequences of COVID-19 on the global and Russian economics. Population and Economics 4, 43-48. https://doi.org/10.3897/popecon.4.e53279.

Braga, F., Scarpa, G.M., Brando, V.E., Manfe, G., Zaggia, L. (2020). COVID-19 lockdown measures reveal human impact on water transparency in the Venice Lagoon. Science of The Total Environment 736, 139612. https://doi.org/10.1016/j.scitotenv.2020.139612.

Cheval, S., Adamescu, C.M., Georgiadis, T., Herrnegger, M., Piticar, A., Legates, D.R. (2020). Observed and Potential Impacts of the COVID-19 Pandemic on the Environment. International Journal of Environmental Research and Public Health 17, 4140. https://doi.org/10.3390/ijerph17114140.

Collivignarelli, M.C., Abbà, A., Bertanza, G., Pedrazzani, R., Ricciardi, P., Miino, M.C. (2020). Lockdown for COVID-2019 in Milan: What are the effects on air quality? Science of The Total Environment 732, 139280. https://doi.org/10.1016/j.scitotenv.2020.139280.

Dobson, A.P., Pimm, S.L., Hannah, L., Kaufman, L., Ahumada, J.A., Ando, A.W., Bernstein, A., Busch, J., Daszak, P., Engelmann, J., Kinnaird, M.F., Li, B. v., Loch-Temzelides, T., Lovejoy, T., Nowak, K., Roehrdanz, P.R., Vale, M.M. (2020). Ecology and economics for pandemic prevention 369, 379-381.

Dutheil, F., Baker, J.S., Navel, V. (2020). COVID-19 as a factor influencing air pollution? Environmental Pollution 263, 114466. https://doi.org/10.1016/j.envpol.2020.114466.

Dutta, V., Dubey, D., Kumar, S. (2020). Cleaning the River Ganga: Impact of lockdown on water quality and future implications on river rejuvenation strategies. Science of The Total Environment 743, 140756. https://doi.org/10.1016/j.scitotenv.2020.140756.

ESA, 2020. Coronavirus lockdown leading to drop in pollution across Europe (2020).

Ficetola, G.F., Rubolini, D. (2020). Climate affects global patterns of COVID-19 early outbreak dynamics. https://doi.org/10.1101/2020.03.23.20040501.

Kerimray, A., Baimatova, N., Ibragimova, O.P., Bukenov, B., Kenessov, B., Plotitsyn, P., Karaca, F. (2020). Assessing air quality changes in large cities during COVID-19 lockdowns: The impacts of traffic-free urban conditions in Almaty, Kazakhstan. Science of The Total Environment 730, 139179. https://doi.org/10.1016/j.scitotenv.2020.139179.

Lal, P., Kumar, A., Kumar, S., Kumari, S., Saikia, P., Dayanandan, A., Adhikari, D., Khan, M.L. (2020). The dark cloud with a silver lining: Assessing the impact of the SARS COVID-19 pandemic on the global environment. Science of The Total Environment 732, 139297. https://doi.org/10.1016/j. scitotenv.2020.139297. 
Li, L., Li, Q., Huang, L., Wang, Q., Zhu, A., Xu, J., Liu, Ziyi, Li, H., Shi, L., Li, R., Azari, M., Wang, Y., Zhang, X., Liu, Zhiqiang, Zhu, Y., Zhang, K., Xue, S., Ooi, M.C.G., Zhang, D., Chan, A. (2020). Air quality changes during the COVID-19 lockdown over the Yangtze River Delta Region: An insight into the impact of human activity pattern changes on air pollution variation. Science of The Total Environment 732, 139282. https://doi.org/10.1016/j.scitotenv.2020.139282.

Lokhandwala, S., Gautam, P. (2020). Indirect impact of COVID-19 on environment: A brief study in Indian context. Environmental Research 188, 109807. https://doi.org/10.1016/j.envres.2020.109807.

Ma, Y., Zhao, Y., Liu, J., He, X., Wang, B., Fu, S., Yan, J., Niu, J., Zhou, J., Luo, B. (2020). Effects of temperature variation and humidity on the death of COVID-19 in Wuhan, China. Science of The Total Environment 724, 138226. https://doi.org/10.1016/j.scitotenv.2020.138226.

Muhammad, S., Long, X., Salman, M. (2020). COVID-19 pandemic and environmental pollution: A blessing in disguise? Science of The Total Environment 728, 138820. https://doi.org/10.1016/j. scitotenv.2020.138820.

NASA, 2020. Airborne nitrogen dioxide plummets over China.

Newton, J., 2020. The Real Story Behind Venice’s Newly Crystal-Clear Canals. AFAR magazine.

Saadat, S., Rawtani, D., Hussain, C.M. (2020). Environmental perspective of COVID-19. Science of The Total Environment 728, 138870. https://doi.org/10.1016/j.scitotenv.2020.138870.

Sajadi, M.M., Habibzadeh, P., Vintzileos, A., Shokouhi, S., Miralles-Wilhelm, F., Amoroso, A. (2020). Temperature and Latitude Analysis to Predict Potential Spread and Seasonality for COVID-19. SSRN Electronic Journal. https://doi.org/10.2139/ssrn.3550308.

Sanchez, L.E., 2013. Avaliação de Impacto Ambiental: conceitos e métodos, 2nd ed. Oficina de Textos, São Paulo.

Selvam, S., Jesuraja, K., Venkatramanan, S., Chung, S.Y., Roy, P.D., Muthukumar, P., Kumar, M. (2020). Imprints of pandemic lockdown on subsurface water quality in the coastal industrial city of Tuticorin, South India: A revival perspective. Science of The Total Environment 738, 139848. https://doi. org/10.1016/j.scitotenv.2020.139848.

Tollefson, J. (2020). Why deforestation and extinctions make pandemics more likely. Nature 584, 175176. https://doi.org/10.1038/d41586-020-02341-1.

Wu, Y., Jing, W., Liu, J., Ma, Q., Yuan, J., Wang, Y., Du, M., Liu, M. (2020). Effects of temperature and humidity on the daily new cases and new deaths of COVID-19 in 166 countries. Science of The Total Environment 729, 139051. https://doi.org/10.1016/j.scitotenv.2020.139051.

Yunus, A.P., Masago, Y., Hijioka, Y. (2020). COVID-19 and surface water quality: Improved lake water quality during the lockdown. Science of The Total Environment 731, 139012. https://doi.org/10.1016/j. scitotenv.2020.139012. 
Zambrano-Monserrate, M.A., Ruano, M.A., Sanchez-Alcalde, L. (2020). Indirect effects of COVID-19 on the environment. Science of The Total Environment 728, 138813. https://doi.org/10.1016/j. scitotenv.2020.138813. 